\title{
Learning Critical Literacy in ESL Classrooms
}

\author{
Guangtian Zhang \\ Center for International Exchange and Education, Baoding University, Baoding, China \\ Email: guangtianz@163.com
}

Received 11 June 2015; accepted 5 July 2015; published 8 July 2015

Copyright (C) 2015 by author and Scientific Research Publishing Inc.

This work is licensed under the Creative Commons Attribution International License (CC BY). http://creativecommons.org/licenses/by/4.0/

(c) (i) Open Access

\begin{abstract}
In this present article, I intend to interpret and argue that Critical Literacy or Critical Language Awareness is a meaningful concept for ESL learners to transparently understand and English educators need to apply it in their daily educational practices. Through reviewing the relevant literatures, the theoretical knowledge of Critical Literacy is introduced at first. The second part concentrates on explaining the importance of implementing Critical Literacy in the instruction of ESL. Finally, rooted in former researchers' findings and argumentations, I elaborate on the analysis of the predictable difficulties and barriers about the cultivation of Critical Literacy for both native and non-native English speakers. In a meanwhile, some suggestive strategies are provided respectfully so as to assist ESL instructors to cope with these problems at the practical stage.
\end{abstract}

\section{Keywords}

Critical Literacy, Critical Language Awareness, ESL, Learning

\section{Introduction}

Critical Literacy (CL), which is also termed as "Critical Language Awareness” (CLA), has become increasingly popular in English educational field in many English speaking countries (e.g., Australia, Canada, New Zealand, the UK, and the USA) since the 1990s. The advocates of CL claim that teaching and learning CL skills is extremely important for students, who are tomorrow's citizens, in the information era (Lohrey, 1998). Towards the education of English as a second language (ESL), the concept of CL is also regarded as beneficial and crucial for ESL learners and has recently been adopted in the instructional practices in different areas across the globe. For example, a number of ESL practitioners in Australia are applying it in their teaching because it not only addresses the social justice and equity of access for their students, but also "reflects a sensitivity to issues of cross-cultural communication and to the potential for cultural values to be imposed" through teaching ESL (Hood, 1998: p. 11).

As an English instructor from China, I am really interested in exploring the values and effectiveness of CL in ESL education, and would like to introduce the theoretical concept of CL and some practical strategies on how 
to use it in classrooms to Chinese ESL teachers and learners. In order to address these issues, this article is divided into three major sections, namely: 1) What is Critical Literacy (CL)?; 2) Why should CL be implemented in the instruction of ESL?; and 3) How to help ESL students to become critical readers?

\section{What is "Critical Literacy" (CL)?}

\subsection{Defining CL}

Traditionally "literacy" refers to the linguistic and functional ability to read and write, while CL expands beyond this basic understanding (Coffey, 2015). To make the notion of CL transparent to learners, many researchers and educationalists have contributed lots of insightful interpretations. Terry Locke (2004) defines,

"CLA [or CL] is an overt consciousness-raising exercise, concerned to make language-users aware of the verbal and non-verbal choices that are and can be made in the production of texts and the ways in which these choices are used to reinforce particular discursive hegemonies" (p. 39).

Duzer, Florez, and Cunningham (2004) also explain that CL encompasses a set of critical and analytical attitudes and skills, which can be applied in the process of understanding and interpreting diverse kinds of texts. Moreover, if concentrating on written language, CL can be understood as a concept that is "concerned with having an understanding of the political and ideological nature of literacy and with being able to question how readers and writers are positioned socially by written texts” (Burns \& Hood, 1998: p. iv).

\subsection{Definitions of Two Relevant Terms}

So as to gain a clearer understanding of CL, there are some relevant terms needing to be learned by ESL educators and learners. According to my own experiences and research, two of these terms are most likely to lead to some ambiguous understandings. Therefore, they are explained respectively, as following:

"Discourse": As Gee (1996) writes, "Discourses are ways of behaving, interacting, valuing, thinking, believing, speaking, and often reading and writing that are accepted as instantiations of particular roles (or "types of people') by specific groups of people" and "Language makes no sense outside of Discourse, and the same is true for literacy" (p. viii). In 1997, Wendy Morgan sums up "Discourse" in four points concerning English education and CL, namely, 1) Discourses sustain and are established by given social practices and institutions; 2) Discourses tend to work in relations with each other; 3) Every Discourse conveys and promotes certain ideology, thus serves the behalf of a particular social group; and 4) Discourses create individuals who live in them.

"Text": A text does not merely refer to a article printed in English textbooks, as most Chinese ESL learners are familiar with and always think of. "A text”, says Lohrey (1998: p. 23), "is any expression, written, spoken, drawn, painted or shown ... [It] is always a co-creation; it is culturally symbolic as well as being a personal construct”. CL is relevant to reading and analysing the social, moral, political and personal meanings that compose every text.

Locke (2004) explained the relationship between "Discourse" and "Text" through exploring the previous works of other scholars of CL (e.g., Halliday and Hasan, 1985; Hodge and Kress, 1988; etc.). He points out that a "Discourse" is a social process "in which texts are embedded in", and a text is both a product of given time and place, which can be analysed and decoded, and a process, which is "necessarily inked to a society's linguistic system” (p.14).

\section{Why Should CL be Implemented in the Instruction of ESL?}

From my perspectives, there are four main reasons for implementing CL in English education both in general and in teaching and learning ESL in particular, described as below:

Firstly, it ought to be noticed that there are two kinds of meanings constructed in texts (i.e., explicit and implicit meaning). Explicit meaning is visible and observed, and always refers to the ostensible content (e.g., the letters of the alphabet in written texts, the lines and colours in visual images, etc.). Implicit meaning, in contrast, refers to all the meanings hidden under the surface "fact" and makes up the major part of all texts. Appling CL in teaching practices will help English learners (including ESL learners) to gain "a critical access to the cultural, social, linguistic and personal contextual meanings associated with, and inherent in, all texts” (Lohrey, 1998: p. 26).

Secondly, as mentioned above in Gee's and Morgan's interpretations of “Discourse”, it needs to be aware that 
language use is not neutral, and texts are not just collections of words and sentences, but are ideological (i.e., a text has bearing on a social theory or worldview, involving beliefs and generalizations about the ways in which the world works) (Gee, 1996; Morgan, 1997). Knobel and Healy (1998) indicate that, although ideology is not necessary to be a conscious/deliberate act of authors or an act of indoctrination, or to lead to some potentially harmful influences, it is really important for English learners (especially ESL students) "to be able to identify ideologies operating in texts, and to be aware of the ways in which ideologies inform and shape author's concept and word choices. Hence, students would learn how to read not only the "word", but also the "world" (Freire, 1972), namely, to make certain of what they are absorbing and how they are affected during reading a text when they agree with and accept what the author is talking about.

Thirdly, Fairclough (1992) points out that it is a period of accelerating social change that we are living in. From his viewpoints, there are three kinds of changes that are related to English language: first, the changes on power and social control from the explicit exercise (i.e., by force) to implicit approaches (i.e., via using "the commom-sense routines of language practice") (p. 3); second, changes in the nature and comparative importance of language practice (e.g., complex communicative skills become more significant for individuals and are treated as vocational skills rather than "life skills" in current society); and third, change in language itself (i.e., change in language practice is more important "in the implementation of more general social and culture change”) (Fairclough, 1992: p. 5). Chris Searle states as well in his book, None but our words: Critical literacy in classrooms and community (1998), "language is vehicle and symbol, message and messenger, carrying change yet expressing the heart of that change itself” (p. 8). It is inevitable for English learners, both native and non-native speakers, to explain language practices critically and link them with the social and power relations underlining them. So the language education, which we, English teachers, are devoted to, needs to involve the critical component, so that our students could be well equipped with the language skills of CL.

Finally, as Vollmer (2002) indicates, although CL work may be risky in an ES/FL context and educators must "carefully consider the cultural implications of asking students to critically examine 'taken for granted' texts, social structures or relations of power" (unpaged), the aims of CL are definitely relevant to the world of TESOL. It is unwise to avoid applying CL in teaching ES/FL because that will make the ESL learners who live in the English speaking countries marginalized from the mainstream school, social and cultural environment that they are actually surrounded by, and make those who live in non-English speaking world have no handy access to better understanding the popular social and cultural issues in the western countries, which may not positively facilitate the cross-cultural communication and cooperation between different countries (i.e., today's internationalizing tendency in economic, educational, and political fields).

\section{How to Help ESL Students to Become Critical Readers?}

Many researchers (e.g., Champman, 1993; Lankshear, 1997; McConnell, 1992; Knobel \& Healy, 1998) point out that the concept of CL is a result of new research in language learning theory and cognitive psychology in the past decade, and the ways of implementing it at practice stages may require further research and development. Therefore, it is no wonder that teaching and learning CL in ESL classroom is a "fresher" topic for most English educators (Wallace, 1992). I am not attempting to argue that the approaches, which are introduced in this part of my writing, are the only or best ones for ESL teachers to apply in their own teaching practices. Rather, I expect that the following suggestions may act as a springboard for other ideas.

Firstly, as McDaniel (2004) states, "the starting point of helping students to be critical readers is for teachers to be critical readers" (p.475). In order to fully develop CL, ESL teachers (as well as English educators in mainstream classes) should understand that there are seven contexts of text (i.e., "the situation", "The text form", "The author/s", “The voice”, "Genre”, Rhetorical strategies", and "World view") (Lohrey, 1998: p. 10), and learn to question from each of them. Then, the teachers can assist their students to achieve this sort of knowledge as well through classroom activities (e.g., Asking students questions, Classroom discussions, Small-group discussions, etc.). Lohrey (1998) provides some significant interpretations on each of these contexts, described as following:

1) The context of situation: It refers to the situation of studying a text and contains two kinds of implicit meanings, namely, what are the teacher's (or institution's) expectations and aims and what the student brings to the text.

Example questions:

a) What are we expected to do and why? What are hidden agendas? 
b) How are students to be marked and assessed? What are the criteria for success?

c) What are the risks and problems in this learning situation?

2) The context of form: In order to be familiar with CL and to master it, students should exercise in a range and diversity of text forms. These text forms refer to various textual forms (i.e., every day texts, literary, science, etc.), and also concern the ways of students' participation, including reading, writing, listening, speaking, viewing, and so on.

Example questions:

a) Why are we studying this text now?

b) What is the explicit topic of this text and what is the cultural setting of the topic?

c) What issues are raised in the text?

3) The context of author(s): There is/are an author/authors for every text, no matter what kind of text it is.

This author context is the principal organizational processes of a text because it is the author(s) who makes/make the decisions on who and what to be involved, and how components to be described in the text. So it relates to the issues of ambiguities in the text, gender, ethnicity, and culture. Though sometimes the context of author is deliberately hidden for some reasons (e.g., to make the saying shown as objectivity), it ought to be aware that there will always be a producer(s) of the text.

Example questions:

a) Who is/are the author/authors? Is authorship hidden? (If so, why?)

b) Is the author's gender or cultural background important here? Why?

c) If you were the author, what values, emphases and agendas would you change?

4) The context of voice: "A voice is a mode of address - it is the voice you heard 'in your head' when reading or writing a passage” (Lohrey, 1998: p. 15). Every text contains voices of the author(s). Generally, voices imply complicit readers, have multiple ingredients (e.g., authority, seduction, formality, informality, etc.), and may be influenced by ambiguity, social or cultural conventions, gender, the rhetoric that is used, and so forth.

Example questions:

a) How many voices are there in the text and belong to whom?

b) How do different voices affect readers?

c) Which the sub-cultures or ethnic groups do the voices come from?

5) The context of genre: Genre in literary studies refers to the formal features of literary texts, such as, epic, epitaph, novel, sonnet, and so on. In literacy education, the notion of genre extends to address the conditions of its institutional and social productions. Moreover, text functions (e.g., report, argument, exposition, narrative) are also relevant to genre.

Example questions:

a) What is the genre of the text? What are the social conditions here?

b) What text functions are used in the genre?

c) How and what other context affect the genre of the text?

6) The context of rhetorical strategies: Rhetorical strategies are contained in every text and serve to persuading the audients to accept what expresses in the text as the truth. This is commonly more apparent in fiction than in non-fiction. Students may need to question and discuss the grammatical constructions and narrative strategies constructed in texts.

Example questions:

a) What is the truth that the text constructs and how are we asked to accept it?

b) Is there a story in the text or behind it?

c) How is the genre of the text constructed by the rhetoric?

7) The context of world view: All texts convey and sustain a world view (i.e., Discourse). As "a broad and all-embracing cultural perspective" (Lohrey, 1998: p. 19), a world view is developed by a series of master narratives, which can be objective or self-reflective. In fact, texts are neither constructed by isolated individuals, nor are created solely by sociocultural and linguistic conventions. So, a text is a co-creation, a process or dynamic result of communication, rather than an object.

Example questions:

a) What is the world view of the text?

b) Is the world view of the text obvious in its genre and rhetorical strategies?

c) Is the world view embedded in the text different of similar to mine? 
Both teachers and students in first or second language learning may not become proficient in CL, if they do not understand what they bring to a text and what is hidden in the contexts of text. In addition, like any other theories, Lohrey's ideas (summarized above) may not be perfect, and people need to read her suggestions critically as well. For example, towards her emphasis of "author context", some other specialists of CL provide different understandings. Locke (2004) states that critical readers generally start from a position of strategic doubt and evaluate texts according to their own perspectives and values as well as those of others. Morgan (2004) also highlights:

"Many of the choices involved [in texts] are social choices, ... since language and the texts made with its resources are constructed within a culture or subculture and for a society in a particular place and time and with particular relationships of power between people” (p. 105).

Hence, as they suggest, CL tends not to strengthen the role of the author played by himself/herself alone, but concentrates more on the discourses that the author is involved in. So, for truly becoming critical readers, teachers as well as learners would need to explore more broadly on the relevant and insightful literature of CL and conduct some action research on this topic by themselves.

Secondly, a number of studies indicate that there are some problematic issues on learning CL in ESL classrooms (Vollmer, 2002). Because ESL students are from/in different social and cultural backgrounds other than those of the Western countries, their CL study is not entirely the same as the one for native English speakers. Jennifer Alford (2001) illustrates some relevant problems, which may occur in using CL in ESL classrooms, and offers some helpful suggestions to cope with these issues. Originally her writing addresses the situations of adolescent ESL students in the mainstream educational context, but from my points of view, her descriptions can be extended to broader areas (i.e., teaching and learning CL in ESL classrooms of high schools and universities in non-English speaking countries).

There are two major issues concluded in Alford's work

The first problem faced by ESL students is that many of them lack of the appropriate background knowledge of historical, social, and cultural issues in western countries. Alford's solution to this problem is to help the students to build these sorts of background knowledge. It can be done under the following suggestions: a) providing the ESL students opportunities to discuss their confusions with native speakers, who have the knowledge, so that their problems can be located; b) the teacher offer them some relevant resources to fill the gaps; secondly, ask students to find and read some related stuff of a given Discourse (e.g., something on the contemporary newspaper) so as to be familiar with the things, such as, the ways the author used to portray perspectives, the types of language used, etc., try to compare these with other Discourses, and then discuss these at class; c) finally, students can use these gained knowledge of the Discourses as the background in their future English language and literacy learning.

Providing background information to the students is also highlighted as an effective teaching strategy of CL by Chapman (1993). She suggests a similar approach with Alford's, and strengthens that teachers should remind students to continuously compare what they are reading with what they have known, and when there are conflicts between the ideas, "they should evaluate the validity of each and determine which ideas need to be modified and how” (Chapman, 1993: p. 69).

The second problem for many ESL students is generated from the culture of learning, in which the authority of the text is unquestionable. Towards this problem, Alford solution is to let the learners understand that CL does not mean to "criticize", change, or deny the poison, but refer to "considering multiple meanings and constructions of social [positions] and Discourses" (Alford, 2001: p. 240).

Exploring relevant works of CL and learning the definitions of this term (e.g., reading the examples listed in the first section of this article) may be helpful for ESL learners to become more comfortable with using CL in their English learning.

In addition, there are some other more specific problems, which maybe occur in implementing CL in ESL classrooms. For example, because of lower English proficiency, ESL students might use their first language to communicate with each other within group discussions, instead of using English (Gilbert, Jacobs, \& Winn-Bell Olsen, 1997). Some educationalists argue that first language use is essential when grappling with a new language and helps scaffold understanding. The linguistic skills, acquired from their vernacular language and culture, may help ESL learners becoming more capable in their analytical orientation of language and in situations, which require verbal communication (Canagarajah, 2002; May, 2002). On the one hand, this sort of ideas is extremely meaningful. On the other hand, English teachers should consider if the students has had sufficient lan- 
guage support (e.g., relevant vocabulary, demonstrations of appropriate language, etc.) to do the task (i.e., learning CL) in the second language.

\section{Conclusion}

To conclude, teaching and learning Critical Literacy (CL) in ESL education is not a simple task. It remains relatively new to ESL students. It is worth conducting and requires efforts from both educators and learners. There are similarities and differences between using CL in the mainstream classrooms in western countries and adopting this concept in ESL classrooms. There are some difficulties for ESL learners as discussed above, but, as Alford (2001) suggests, there is one advantage for them when using CL, namely, that they may easily resist the intention of the author, because they are not the predicted audience.

In the era of internationalization and change, CL will become more popular and attractive for more English educators in China as well as in other countries across the world. Therefore, further research on how to successfully implement CL in ESL classrooms will be certainly needed in the near future.

\section{References}

Alford, J. (2001). Learning Language and Critical Literacy: Adolescent ESL Students. Journal of Adolescent \& Adult Literacy, 45, 238-242.

Burns, A., \& Hood, S. (Eds.) (1998). Teachers’ Voices 3: Teaching Critical Literacy. Sydney: NCELTR of Macquarie University.

Canagarajah, S. (2002). Multilingual Writers and the Academic Community: Towards a Critical Relationship. Journal of English for Academic Purposes, 1, 29-44. http://dx.doi.org/10.1016/S1475-1585(02)00007-3

Champman, A. (Ed.) (1993). Making Sense: Teaching Critical Reading across the Curriculum. New York: The College Entrance Examination Board.

Coffey, H. (2015). Critical Literacy. http://www.learnnc.org/lp/pages/4437\#theory

Duzer, V., Florez, C., \& Cunningham, M. (2004). Critical Literacy for Adult Literacy in Language Learners. http://www.ericdigests.org/2001-1/critical.html

Fairclough, N. (1992). Introduction. In N. Fairclough (Ed.), Critical Language Awareness. London: Longman.

Freire, P. (1972). Cultural Action for Freedom. Harmondsworth: Penguin.

Gee, J. P. (1996). Social Linguistics and Literacies: Ideology in Discourse. London: Taylor and Francis.

Gilbert, C., Goldstein, S., Jacobs, G. M., \& Winn-Bell Olsen, J. (1997). Six Questions and 58 Answers about Using Cooperative Learning. ThaiTESOL Bulletin, 10, 16-24.

Hood, S. (1998). Critical Literacy: What Does It Mean in Theory and Practice? In A. Burns, \& S. Hood (Eds.), Teachers' Voices 3: Teaching Critical Literacy (pp. 11-19). Sydney: NCELTR of Macquarie University.

Knobel, M., \& Healy, A. (Eds.) (1998). Critical Literacies in the Primary Classroom. Newtown: PETA.

Lankshear, C. (1997). Changing Literacies. Philadelphia, PA: Open University Press.

Locke, T. (2004). Critical Discourse Analysis. London: Continuum.

Lohrey, A. (1998). Critical Literacy: A Professional Development Resource. Melbourne: Language Australia.

May, S. (2002). The Problem with Literacy: Keynote Address to NZATE Annual Conference. English in Aotearoa, 48, 4-14.

McConnell, S. (1992). Literacy and Empowerment. The Australian Journal of Language Literacy, 15, 123-138.

McDaniel, C. (2004). Critical Literacy: A Questioning Stance and the Possibility for Change. The Reading Teacher, 57, 472481.

Morgan, W. (1997). Critical Literary in the Classroom: The Art of the Possible. London: Routledge.

Morgan, W. (2004). Critical Literacy. In W. Sawyer, \& E. Gold (Eds.), Reviewing English in the 21st Century (pp.103-114). Sydney: Phoenix Education.

Vollmer, G. (2002). Book Review: Negotiating Critical Literacies in the Classroom. http://tesl-ej.org/ej22/r10.html

Wallace, C. (1992). Critical Literacy Awareness in the EFL Classroom. In N. Fairclough (Ed.), Critical Language Awareness (pp. 59-92). London: Longman. 